\title{
ANTROPOLOGIA DEPOIS DO "FIM DA TEORIA"
}

\author{
Giulle Vieira da Mata \\ Universidade Federal de Ouro Preto - Brasil
}

Resumo: $O$ artigo propõe a definição de etnografia nos termos de Rickert: uma narrativa antropológica que figura uma sintese da realidade, ou melhor, um "conceito de realidade". Sua função é reduzir a complexidade do real para permitir que ele seja apreendido e pensado. Nesse sentido configura uma "redução" da diversidade e da complexidade histórica e cultural; um instrumento eficiente para o antropólogo que reconhece o problema da relação entre explicação da realidade e sua "imprevisibilidade", mas que se recusa a desistir da ideia de ciência como forma de organização do conhecimento.

Palavras-chave: etnografia, narrativa antropológica, "sintese da realidade", teoria.

\begin{abstract}
The paper proposes a definition of ethnography in Rickert's terms: an anthropological narrative that is a "synthesis of reality", or rather a "concept of reality". Its function is to reduce the complexity of reality in order to allow it to be perceived and to be thought. In this sense, all ethnography is a "reduction"; an efficient tool for the anthropologist who recognizes the problem of the relationship between explanation and unpredictability of reality, but who refuses to give up the idea of science as a way of organizing knowledge.
\end{abstract}

Keywords: anthropological narrative, ethnography, "synthesis of reality", theory.

Parto do pressuposto de que fazer "ciência social" é estudar sistematicamente uma realidade que é única com a intenção de produzir um objeto inteligivel, já que o real não se dá a pensar se não for condensado, seja na forma de narrativas, seja na forma de conceitos; o que Heinrich Rickert chamou de "síntese da realidade". Vejamos o que pretendo dizer com isso.

As implicações do movimento pós-modernista para a noção de ciência social são evidentes. Os princípios pós-modernos de incerteza - ou melhor, de certeza da inacessibilidade do real - culminaram em críticas de ordem epistemológica que invalidam todo e qualquer esforço de generalização. Os

Horizontes Antropológicos, Porto Alegre, ano 18, n. 37, p. 185-208, jan./jun. 2012 
filósofos da linguagem declararam a impossibilidade de expressão dos fatos: nunca podemos dizer nada verdadeiro porque a linguagem é autorreferente e, por isso mesmo, incapaz de alcançar a realidade. Foi a partir desse raciocínio que boa parte dos profissionais da antropologia passou a identificar a sua disciplina como disciplina literária: os valores da antropologia como ciência social foram substituídos pelos valores da literatura, cujo pressuposto é a "certeza" de que não se pode fixar o sentido objetivo a um discurso. O que existe é apenas a interpretação subjetiva. O resultado é uma espécie de teoria da relatividade absoluta que sentenciou o fim da teoria.

Assim, as etnografias passaram a ser entendidas como reduções da diversidade e da complexidade histórica e cultural. Com isso, a rejeição de qualquer coisa que se aproxime da ideia de "princípio de causalidade". Segundo essa orientação, ao pensamento é vetada a possibilidade de identificar ao acontecimento um "centro". É nesse sentido que podemos dizer que essas "novas certezas" aplicadas à antropologia acabaram desaguando em solipsismo teórico. Toda teoria tornou-se suspeita.

Daí para a recusa do pressuposto de que algo como $a$ ciência ou $a$ racionalidade exista, foi um pulinho. De fé cega no status especial do conhecimento científico passamos ao ceticismo fundamental em relação à ciência. Todos os que se dedicam à tentativa de compreensão da realidade das formas de sociação foram acusados de "caçadores da verdade" pelos pós-modernistas que - ao contrário de seus colegas ingênuos - são os verdadeiros caçadores de mitos: no caso, a ciência e a ideia de método. Nesses termos, o conhecimento científico passa a não diferir de outras atividades humanas: é sobredeterminado pela cultura que o produz. O que vemos através dos óculos da ciência como sendo "realidade" é, antes, uma construção sociocultural, exatamente como o é a arte ou o texto literário. $\mathrm{O}$ conhecimento científico se encontra irremediavelmente atado a esquemas conceituais, linguísticos. Por isso a ciência não poderia nunca constituir acesso privilegiado, muito menos direto, à realidade como quiseram os modernos. Ela é uma maneira de falar, de classificar e de agir como tantas outras, e que tão somente é tomada como privilegiada porque "funciona", à medida que produz (torna real) categorias.

Essa radicalização do caráter de constructo fechado numa espécie de "prisão da linguagem" tem a etnografia em conta apenas como representação. ${ }^{1}$

1 Sobre a desintegração da autoridade etnográfica, ver Clifford (1998) e sua caçada aos "elementos míticos" da etnografia.

Horizontes Antropológicos, Porto Alegre, ano 18, n. 37, p. 185-208, jan./jun. 2012 
A realidade passa a ser definida como produto da linguagem. E se a língua é o fundamento do mundo, não existe etnografia, já que, enquanto estamos dentro de uma cultura não podemos acessar o que há fora dela. Tudo o que fizermos vem culturalmente, já que cultura tornou-se um conjunto de hábitos espontâneos tão profundos que somos impossibilitados até de examiná-los. É o argumento que protege de qualquer crítica a teoria pós-moderna - se é mesmo de uma teoria que estamos falando.

São vários os autores que insistem na impossibilidade de se separar fase da pesquisa e fase da apresentação. ${ }^{2} \mathrm{E}$ desde então acreditamos que não há como separar observação de teoria, uma vez que os fatos são mera matériaprima conformada pela narrativa. Desde o primeiro minuto da pesquisa, o problema da interpretação se impõe de forma absoluta. A relação essencial entre pesquisa empírica e produção do texto etnográfico é de (con)fusão, porque contato com "o outro" implica necessariamente a produção imediata de textos. Ao concluírem, portanto, que estabelecer fatos é um processo estafante dada a complexidade do mundo real, não são poucos os que optam por desistir de tentar organizá-los, ou seja, desistem da "ciência".

No caso, a relação referencial possível entre narrativa e realidade sequer é mencionada. O problema do uso da intertextualidade (narrativas referem-se umas às outras; não à realidade), também não. No fim, o que sempre é interpretado é o "efeito de verdade" dos textos, assim como o conhecimento que se constrói a partir deles é uma espécie de "efeito de conhecimento". Sendo assim, o que os antropólogos produzem não é ciência, ainda que se ocupem de causas e da elaboração de conceitos. Seus textos são meras lentes através das quais a realidade pode ser vista "com outros olhos", sendo úteis tão somente enquanto possibilitam a experimentação do que é o "saber local". ${ }^{3}$ Constituem a massa sobre a qual, então, os pós-modernos trabalham para desvendar um esforço inútil de "relato do saber científico ocidental".

A contraface desse desespero teórico-metodológico é o "realismo ingênuo" de que falava Dilthey: a crença na capacidade da ciência para reproduzir

\footnotetext{
Cf. Marcus e Fischer (1986), Marcus (1994), Rosaldo (1990) e Clifford (1998).

Há em autores que partilham desse tipo de premissa - especialmente em Crapanzano (2004) - uma apologia radical da autonomia do texto, com suas possibilidades ilimitadas de interpretações mediante a referência a outros textos (intertextualidade). A investigação transforma-se, para eles, em uma espécie de caça a ambivalências que se faz através do uso do texto contra ele mesmo (desconstrução).
}

Horizontes Antropológicos, Porto Alegre, ano 18, n. 37, p. 185-208, jan./jun. 2012 
o real na sua integridade, seja na narrativa antropológica, histórica ou sociológica. Assim, tomemos o virtuoso caminho do meio do qual falam os chineses. Com Rickert (1921) entendo o real como algo "irracional", no sentido de que nenhuma narrativa é capaz de esgotá-lo. Contudo, não dispomos de outra forma de abordá-lo senão por meio da narrativa - histórica para Rickert, antropológica para mim -, narrativas que configuram uma síntese da realidade - um "conceito de realidade", como Rickert preferia dizer - cujos elementos fundamentais devem ser selecionados. Seja na história, seja na antropologia, tratamos de individualidades, o que não significa dizer que a antropologia ou a história deixem de ser ciências. $\mathrm{O}$ foco está na diferença e no particular, mas sem abdicar do conceito ou da etnografia - mais uma vez, uma síntese da realidade - como instrumento para operar totalizações.

Fundador de uma corrente fundamental da tradição das "ciências culturais" (Kulturwissenschaften), Rickert ensina que não dá para entrar em crise (as crises de paradigma, de representação, da autoridade etnográfica) toda vez que nos damos conta de que a História não converge para um telos. Antes, ela produz dispersão, particularidades, singularidades. Mas se o esforço de identificação sujeito-objeto é a fonte de todas as crises, se toda interpretação está aprisionada a seu tempo e o distanciamento não tem qualquer serventia, porque continuamos fazendo ciência social? Em outras palavras: se a "fonte primária" da ciência que quero praticar são os textos e todas as interpretações são arbitrárias, porque continuar interpretando? Esse sentimento pode ser resumido nas palavras do próprio Rickert (1921, p. 134-135, tradução minha):

Tão logo é pensado até suas últimas consequências, o historicismo [...] revela-se uma forma de relativismo e de ceticismo, e, como qualquer outro relativismo, se for levado a efeito de forma consequente, só pode conduzir a um total niilismo.

Para o caso da antropologia, basta substituir "historicismo" por "pósmodernismo". Malinowski insistiu num conceito científico de cultura quando detectou na ciência etnológica esse déficit de observação. $O$ mesmo fundamento orientou o funcionalismo quando da escolha a dedo de objetos que se submetiam à observação de regras e quantificações. O modelo de ciência ali era único: fazer ciência, assim como fazer antropologia, era buscar leis universais. Mas existiria apenas um modelo de ciência? Apenas um modo de fazer ciência? 
Decerto que não. Provavelmente, Rickert (1961) entenderia a "narrativa antropológica" da mesma maneira como entendeu a "narrativa histórica". Veria nela uma ciência, já que ela elabora e opera conceitos cuja função é reduzir a complexidade do real, possibilitar que ele seja pensado, apreendido. E o fato de os conceitos da antropologia se referirem a realidades investidas de valor não é empecilho algum, já que ao cientista que se ocupa com os fenômenos culturais cabe reconstituir "individualidades", e não elaborar leis gerais. Em outros termos, o que Rickert (1921, p. 231, tradução minha) ensina para a história, valeria para a antropologia:

O problema da conceituação histórica está [...] em se é possível um rearranjo e uma simplificação científica da realidade sem que, simultaneamente, dela se perca - como é o caso das ciências naturais - a individualidade, e, todavia, não se forme uma mera "descrição" de fatos, a qual ainda não deve ser vista como uma exposição científica.

Sob o prisma de Rickert, de fato as etnografias continuam a ser entendidas sim como reduções de complexidade histórica e cultural, tal como denuncia o movimento pós-moderno. Redução, porém, num sentido positivo, pois é exatamente como síntese de uma realidade que uma "narrativa antropológica" permite a apreensão do real. Nem a história, nem a antropologia, desde que compreendidas como ciências individualizantes, preocupadas com singularidades, precisariam lançar mão de métodos ou conceitos generalizantes (como fazem as ciências naturais) a fim de afirmar sua cientificidade. O que não significa dizer que a exposição antropológica se confunda com uma mera descrição, como querem os pós-modernos. Ao descrever seu objeto, o antropólogo tem de relacioná-lo a um contexto, tem que estudar as redes causais que a ele se relacionam sem cair no equívoco de supor que falar em causalidade significa necessariamente falar de "leis". A atração da outra margem também é fatal: o nominalismo pós-moderno e sua condenação de toda investigação de conexões causais.

Sempre haverá um princípio da "seleção do essencial" a partir de valores, uma vez que o antropólogo nunca estará em condições de isolar todas as causas de um evento ou processo social. O que o antropólogo faz é selecionar e analisar aquelas que considera significativas. E não há problema algum nisso se nos colocamos do lado de Rickert, para quem a história não deixa de 
ser ciência porque o historiador se deixa guiar por valores quando compõe suas "exposições históricas". Assim, a etnografia deve ser entendida como um "conceito de uma dada realidade", um conceito que, por sua vez, é síntese daquilo que é essencial no real, à luz do que se deseja esclarecer, uma síntese obtida à custa de esforço sistemático de compreensão-explicação de uma particularidade comparável a outras.

Tal como Gellner (1992), não quero aqui insistir numa oposição absurda entre racionalidade e cultura a partir do momento em que identifico "o fazer antropológico" como algo que é ao mesmo tempo cultural (é e está em uma cultura) e cognitivo (sistemático). Penso que, quando sabemos que os resultados apresentados ao fim de uma investigação têm algumas de suas raízes em convicções ou consensos sociais, isso não nos obriga necessariamente a declará-los como inúteis. Quando reconhecemos que o "fazer antropológico" está aninhado em uma cultura, isso não deve significar uma declaração de guerra explícita à possibilidade de organização do conhecimento sobre um dado fenômeno. O significado e os valores da "objetividade" podem ser conflitantes com relação a algumas normas epistemológicas, mas de maneira alguma têm a ver com irracionalidade.

Devemos atentar primeiramente para o fato de que há diversas formas de racionalidade, como bem ensina Weber; e, segundo, que cada uma delas opera com pressupostos culturais diversificados. E é aqui que volto àquele que foi meu primeiro objeto de pesquisa antropológica: as lendas contemporâneas. Narrações que me propus pesquisar como uma daquelas formas de racionalidade, que operam com valores e que constituem também "sínteses da realidade" à qual se referem. Resultam daquele esforço contínuo e ininterrupto de apreensão do real que condiciona nossa vida.

Vejamos mais de perto - ou seja, sem separar apresentação de explicação - como se realiza uma pesquisa nos termos aqui defendidos a partir das considerações retiradas do que gosto de chamar de meu diário de pesquisa.

No semestre de verão de 1999 tive a oportunidade de frequentar, na Universidade de Colônia (Alemanha), meu primeiro seminário com o Prof. Dr. Ion Taloş, um estudioso da tradição oral dos países de língua neolatina (em especial Espanha e Itália). Ao final do semestre, vendo minha empolgação pela Volkskunde, em especial pelos estudos de narrativa popular, o professor chamou-me para uma conversa que foi decisiva para mim: "Você deve escolher um objeto de pesquisa ao qual procure se dedicar de forma sistemática, e

Horizontes Antropológicos, Porto Alegre, ano 18, n. 37, p. 185-208, jan./jun. 2012 
com o firme propósito de organizar o conhecimento a seu respeito. A atração da narrativa popular é fortíssima e não são poucos os que se satisfazem em colecionar borboletas."

Argumentei sobre a dificuldade de "escolher". Não sabia como fazê-lo, e a partir de quais critérios. A resposta do professor foi simples e encantadora. Contou-me como chegou, ele mesmo, ao seu primeiro objeto, a colind $\breve{a}$ romena sobre "O pastor e a ovelha". ${ }^{4} \mathrm{Na}$ época, seu professor de graduação em folclorística havia lhe dado a pista: "procure em casa". Nas férias, quando voltou à Romênia, ouviu sua mãe cantar o romance. Mas ouviu de outra maneira, "com outros ouvidos, aquilo já havia ouvido tantas vezes na vida". Taloş decidiu naquele momento o que iria pesquisar. Depois de me contar sua história, reforçou a lição aprendida, como que para garantir a transmissão da experiência: "procure em casa!"

Um ano se passou até que pude voltar a casa. Em julho de 2000 viemos, meu marido e eu, passar uma temporada de três meses no Brasil. Durante o período em que estive na Alemanha, meus pais resolveram se mudar para a zona rural (um sonho antigo). Compraram uma fazenda às margens do rio das Velhas, num lugarejo chamado Maquinezinho (distrito de Cordisburgo, MG), a duas horas de Sete Lagoas, minha terra natal. Lembro-me até hoje de minha mãe apresentado-me o lugar. A fazenda dos Crioulos era muito antiga e sobre ela contavam-se muitas histórias. E minha mãe, que não perde uma boa história, logo cuidou de me informar de todas. ${ }^{5}$ Mas uma delas chamou minha atenção de forma diferente, embora eu já a conhecesse de longa data:

Ali no capão do meio tem uma gruta, uma lapa, onde os Piriás ficaram escondidos. Seu Antônio chegou a ver os dois aqui. O dia que a polícia chegou, achou na gruta os pertences: algumas pilhas de rádio, anzol, chumbada e uma lata com farofa de passarinho, ainda quente. A fogueira ainda queimava. Nem tiveram tempo de comer.

4 Trata-se de uma narrativa em verso, cantada, muito conhecida no interior da Romênia. A este "cantar de Mioriţa" dedicou-se ninguém menos que Mircea Eliade (1982, p. 235-267), que se refere a essa ballade como "tesouro do povo romeno". Uma tradução do romance foi feita por Michelet em 1854.

5 Teria sido a fazenda mais rica da região, no tempo dos escravos, que desembarcavam ali trazidos de barco pelo rio das Velhas. Mas também na época do sr. Lelé, o grande fazendeiro do lugar, de cujo filho caçula meu pai havia adquirido o terreno. Dizem que do chão brotava ouro e cristal. A terra era a mais fértil das redondezas, uma fartura só. O lugar era guardado por uma luz que anda e persegue os forasteiros: dizem que é o espírito de um escravo que morreu para defender seu patrão. Dele podem-se ouvir os gemidos à noite.

Horizontes Antropológicos, Porto Alegre, ano 18, n. 37, p. 185-208, jan./jun. 2012 
Meu pai completava as "informações" com alguns detalhes que ouvira do seu Antônio, antigo vaqueiro da fazenda dos Crioulos.

Meus pais narravam o caso com uma espécie de orgulho de agora fazerem parte da História: moravam num lugar que havia servido de refúgio aos famosos Irmãos Piriás.

O nome Piriá funcionou naquele dia como uma senha de acesso a um mundo que nunca tinha se revelado a mim daquela maneira, embora estivesse estado sempre ali, ao meu alcance, e me fosse tão familiar. Naquele dia "escolhi" meu objeto. E agora estava claro o critério a ser usado nessa "escolha": era preciso olhar com outros olhos para meu próprio mundo.

Primeiro gostaria de descrever esse mundo outro. Um fato acontecido no mês de abril do ano de 1978 provocou e ainda provoca comentários em Sete Lagoas e região. Depois do que muitos classificam como um "incidente com a polícia", os irmãos Sebastião e Orlando Patrício da Costa tornaram-se celebridades e sua fama se espalhou. Um registro do apanhado de detalhes que compõem não os fatos, mas esses "causos" sobre os Piriás, ficaria mais ou menos assim:

Os Piriás eram dois irmãos que foram para Sete Lagoas atrás de trabalho, vindos da região da Serra do Cipó. Na cidade, pegaram de empreitada uma cerca pra fazer na fazenda de seu Culego. Terminado o serviço, o fazendeiro (que era turco) não quis pagar, porque achou que o serviço foi feito rápido demais. Os irmãos, então, começaram a cobrar insistentemente. $\mathrm{O}$ fazendeiro se sentiu ameaçado e chamou a polícia. Resultado: um dos irmãos foi preso, acusado de roubo de um rádio. Depois de solto, junto com o irmão, voltaram a cobrar do fazendeiro, que chamou a polícia novamente. Na fuga, os dois acabaram por matar um policial com um tiro no meio da testa lá na Lapa da Branca, onde é hoje o bairro Padre Teodoro. A polícia tinha que vingar o parceiro. Iniciou então uma perseguição aos Piriás que durou mais de seis meses, dentro de uma área compreendida ao sul por Sete Lagoas e ao norte por Diamantina. Os dois eram excelentes mateiros. Conheciam bem as redondezas e escapavam com facilidade. Chegaram a matar vários policiais. A polícia só conseguiu matar os dois na noite de Natal daquele mesmo ano.

Trata-se de uma versão sistematizada e ampliada do que chamei de lendas sobre os Irmãos Piriás, e que também difere muito das versões dos narradores no mundo real - que, no caso, são relatos que apresentam uma forma muito diferente de combinar os "fatos", de se relacionar com as possíveis 
"ambiguidades" que aparecem no decorrer da construção da narrativa, de aplicar a "imaginação", de legitimar suas "afirmações" e, principalmente, de interpretar o que vem a ser "realidade".

Eis alguns itens que constam desses "casos" sobre os Piriás, indispensáveis para se adquirir uma noção mais clara da maneira como os interlocutores da lenda efetuam sua relação com o acontecido. A prisão do irmão cujo apelido era Caolho teria sido realizada a mando de um fazendeiro poderoso, ex-patrão dos Piriás. Na prisão o moço teria apanhado muito. Dizem inclusive que ele teria sido castrado; daí o ódio e a vingança: por isso eles só matavam policiais. Os Piriás eram exímios atiradores e só matavam com tiro na testa. Tinham o corpo fechado (disso praticamente ninguém duvida). Eram anfíbios, podendo ficar horas embaixo d'água. Conseguiam percorrer léguas e léguas em um só dia. Na fuga, podiam se transformar em cupim, arbustos e até mesmo em policiais, com farda e tudo, e era assim que conseguiam informações sobre diligências futuras. A bússola dos dois era o rádio à pilha, que informava dos passos da polícia. A sua guardiã mais fiel era uma cadela, que os policiais teriam matado covardemente. "E que morreram que nada!" - ouve-se sempre, e em seguida a explicação: na verdade, a notícia da morte dos Piriá foi plantada pela polícia para abafar a vergonha de ter sido desmoralizada por dois caboclos analfabetos.

O drama dos Piriás virou assunto na cidade de Sete Lagoas e região, suscitando as mais variadas formas de expressão. Um cordel e uma novela foram escritos. Dois filmes (um curta e um longa-metragem) foram rodados e há o projeto de um terceiro. Para além da região, os Piriás foram notícia até mesmo no Jornal Nacional. A imprensa mineira deu grande destaque ao caso. Não faltou espaço sequer para as lendas:

[...] a fama dos irmãos Orlando e Sebastião Patrício cresceu assustadoramente na zona rural de Sete Lagoas. Em todos os locais de reunião, se contavam estórias sobre os dois irmãos. Uma das lendas mais contadas, e que logo correu de boca em boca, dava conta de que Orlando e Sebastião viviam no mato há muito tempo, desde o dia em que teriam assassinado a própria mãe. Esta, pouco antes de morrer, teria lançado uma praga nos filhos, dizendo que, eles iriam passar o resto de suas vidas, como animais selvagens, dormindo no mato e perseguidos, sem poder dormir duas noites no mesmo lugar.

Outra estória que logo se tornou popular falava que eles tinham corpo fechado e parte com o diabo e por isso nunca seriam feridos pelas balas disparadas contra

Horizontes Antropológicos, Porto Alegre, ano 18, n. 37, p. 185-208, jan./jun. 2012 
eles. Esta versão surgiu em virtude da maneira usada pelos Piriás para fugir aos constantes cercos. Atirando sempre e rodopiando o corpo sobre si mesmo, eles tentavam se transformar num alvo difícil para os militares que os caçavam. Além disso, a pontaria sempre certeira de um dos Piriás era motivo de conversa em todos os locais e o povo começou a criar um mito em torno de seus nomes. [...] Algumas pessoas diziam que a guerra que Orlando e Sebastião travavam contra a polícia fora causada por maus tratos recebidos durante a prisão, e que teria deixado cego um deles. Desde esse dia, eles teriam feito um juramento de lutar até a morte contra qualquer policial e não maltratavam as pessoas que encontravam em seu caminho. ${ }^{6}$

Sempre achei que narramos histórias porque julgamos que elas merecem ser ouvidas. E contamos muitas histórias. Sempre e tantas, que o ato de narrálas é como que naturalizado. Digo isso por mim, que venho de uma família em que as pessoas gostam muito de contar caso. Narrar constituiu para mim, desde sempre, algo natural, parte do processo também natural e necessário de transmissão de experiências. Uma forma de trabalhar incertezas, temores, de legitimar visões de mundo e papéis sociais, de participar de uma espécie de política de identidades. As narrativas compartilhadas sempre me pareceram vir para aconselhar, criticar indolências e incompetências, prescrever condutas, exatamente quando são capazes de (co)mover aqueles que ouviam. Por meio de histórias as pessoas se empenham na avaliação de comportamentos e instituições além de abastecerem a memória com acontecimentos espetaculares. Moral-discurse enfim, já que se oferecem nos termos de Johannes Stehr (1998) como recurso moral. Narradas em momentos considerados ideais para compartilhar um tipo específico de experiência. Configuram assim estratégias de moralização, uma tentativa de formação de uma opinião "pública". Delas se vale para elogiar ou satirizar, criticar ou incentivar. ${ }^{7}$

As histórias sobre os Irmãos Piriás podem ser reduzidas ao conceito de lendas contemporâneas para que possamos pensá-las na sua função de atualização da experiência de valores nesse sentido. Trata-se de um tipo específico

6 Diário da Tarde, 27/12/1978, que concedeu espaço para os “causos". Conferir também Estado de Minas, 27/12/1978, onde a preocupação maior parece ter sido fornecer a versão dos acontecimentos em termos oficiais.

7 Uma excelente análise dessas modernen Sagen em sua função de moralização foi feita por Johannes Stehr (1998). Devo muito de minha argumentação, nesse particular, à leitura desse livro, escrito a partir do que há de mais recente nos assim chamados cultural studies.

Horizontes Antropológicos, Porto Alegre, ano 18, n. 37, p. 185-208, jan./jun. 2012 
de gênero narrativo, marcado por um ininterrupto desdobramento do significado atribuído a um determinado evento; resultado e, ao mesmo tempo, instrumento de formalização da relação de uma "comunidade de comunicação" com um dado acontecimento em termos bem diferentes do que os que descrevem "o que realmente aconteceu". Trata-se de formalização das "impressões" do evento que se faz a partir de uma tomada de posição no que diz respeito aos critérios de avaliação de conduta dos sujeitos envolvidos na situação. Essa tomada de posição se revela tanto na maneira como as pessoas descrevem a atitude dos personagens das lendas quanto na forma e na escolha do momento de narrar (e isso independentemente do que realmente tenha acontecido). Ao participar desses momentos narrativos, os interlocutores trabalham com expectativas morais e promovem a manutenção do consenso moral de sua comunidade de comunicação relativo aos pressupostos normativos do comportamento adotados no decorrer do conflito entre os dois irmãos e a polícia. Segundo a avaliação de quem partilha a lenda, trata-se de confirmar a validade de pressupostos que, no entendimento dos interlocutores, não vigoraram.

No caso, essas lendas, como formas de representação moral do cotidiano, giram em torno da violação do consenso moral que deveria orientar as interrelações entre civis e policiais (além de patrões e empregados). Essa violação, vivenciada como privação do reconhecimento social, acabaria por motivar o reexame coletivo das instituições, dos papéis sociais, das formas de interação social, tudo isso por meio das lendas sobre os Irmãos Piriás. Parece que todos os que narram histórias sobre esses dois irmãos concordam sempre, tanto no que diz respeito a quais expectativas morais deveriam ser preenchidas no intercurso das relações do dia a dia entre indivíduos e instituições quanto na certeza de que tais expectativas teriam sido lesadas num processo fracassado de socialização dos irmãos no ambiente urbano. Por isso, o centro moral das narrativas sobre os Piriás constitui-se na descrição de uma situação de "experiência de reconhecimento" denegado, de um sentimento de vergonha social no sentido de Axel Honneth (2003). O momento narrativo dessas histórias configuraria, portanto, uma oportunidade para o debate público sobre a privação de direitos considerados fundamentais; descreveriam a priori uma luta cotidiana pela honra, por reconhecimento social (Honneth, 2003). Para no fim os Piriás conquistarem estima social por meio da ampliação da representatividade da (re)ação dos dois irmãos contra uma experiência interpretada como de agressão moral. Os sentimentos, que as lendas movem e que movem as lendas, 
se orientam pelas pretensões desse reconhecimento e desse respeito por parte dos indivíduos, tanto os que compõem o corpo de personagens das histórias quanto os que narram os feitos desses personagens.

Daí a necessidade de se atentar para os sentimentos morais que atuam no cotidiano das pessoas que contam coisas sobre os Piriás, com foco privilegiado nas normas morais de ação. Ao contar as histórias, as pessoas assentem e encorajam a atitude dos irmãos; nelas os dois adquirem voz e referem-se a si mesmos como seres dotados de habilidades especiais reconhecidas pela comunidade de valores que fala deles. A valorização do significado social dos sentimentos morais envolvidos no processo de conto/reconto dessas histórias passa a ser assim o foco da investigação antropológica e a pesquisa se volta para a cultura moral cotidiana da comunidade de comunicação e para a narração como ação social.

Note-se que são histórias que têm existência em si na medida em que são observáveis em seu "uso", em sua aplicabilidade nas interações sociais. Daí seu poder de atração como objeto de pesquisa antropológico. Trata-se de forma de sociação que pede - se assim posso me expressar - uma antropologia da socialização interessada em apreender as estratégias de interação envolvidas na narr-ação e em identificar a maneira como tais narrativas se relacionam com a realidade.

A organização do conhecimento quanto ao tema pode ser feita a partir de diferentes orientações teóricas, onde se encontram diversas "trilhas intelectuais" (Madan, 1994) e se promove o "cruzamento de fronteiras disciplinares" (Kofes, 2001, p. 13). A opção por uma abordagem inclusiva em termos teóricos, esse encontro de culturas teóricas na mente do pesquisador, facilita a compreensão do evento. ${ }^{8}$ E o primeiro benefício é a atenção para a necessidade de se precisarem os conceitos, nos termos de Rickert. Um exemplo da necessidade dessa precisão. As histórias sobre os Irmãos Piriás se colocam na fronteira entre dois conceitos caros aos estudos de folclorística, sobre os quais os próprios especialistas não conseguiram firmar um consenso. São eles os conceitos de lenda contemporânea e lenda urbana, e que, na maioria das vezes, são tomados

\footnotetext{
8 A inspiração vem de T. N. Madan (1994, p. 138-139, 159), em especial de sua defesa a favor de uma antropologia produzida a partir de quadros teóricos mais abrangentes. Para a importância da perspectiva de Madan nesse sentido, conferir Peirano (2006).
} 
como sinônimos. ${ }^{9}$ Mas a sinonímia incomoda, ou melhor, não esclarece. O uso indiscriminado das duas expressões gera no mínimo um desconforto, já que, sem o devido refinamento, nenhum dos dois conceitos cobre o objeto.

O termo "lenda contemporânea" define o objeto pela proximidade no tempo. Nesse sentido, as histórias sobre os Piriás não seriam contemporâneas stricto sensu, já que tudo aconteceu há quase três décadas. Contudo, as histórias são narradas ainda hoje. E por isso, o ato de narrar é ação contemporânea.

Já o termo "lenda urbana" delimita, por sua vez, o objeto no espaço. O que rebate em um problema de ordem metodológica: a Sete Lagoas da época dos Piriás (1978) não era necessariamente o que poderíamos chamar de espaço urbano moderno. Era mais um contexto de rurbanidade, para usar a expressão de Gilberto Freyre. E essa (con)fusão entre rural e urbano não se dava somente na esfera da organização do espaço ou da vida na cidade. Ela é gritante quando se vê naquela Sete Lagoas dois códigos em vigor: um de comunidade profundamente tradicional com tudo o que a palavra tradicional comporta; e outro moderno, tentando garantir o moderno estado de direito. $\mathrm{O}$ espaço urbano de Sete Lagoas adotou de jura esse segundo código, embora, no tempo dos Piriás, fosse ainda de fato lugar onde a confusão entre esfera pública e privada, direito e privilégio, ainda fosse uma realidade.

O trabalho de campo evidenciou ainda mais a ineficiência do conceito "lenda urbana" para os casos sobre os dois irmãos. As narrativas recolhidas na zona rural do município diferem qualitativamente daquelas que recolhi na região urbana. Seja no que diz respeito à menor permeabilidade ao sobrenatural ou ao maior grau de humor, as versões "urbanas" da história dos Piriás são diferentes.

A opção pelo conceito "lenda contemporânea" se confirma então. Usamse três parâmetros principais para defini-la:

a) a lenda contemporânea tem por base um fato histórico;

b) quem narra uma lenda contemporânea oferece o caso como sendo verdadeiro;

c) a narrativa pode parecer parcial ou totalmente absurda para aqueles situados fora da comunidade narrativa.

\footnotetext{
9 Não seria o caso de abordar a discussão tal qual ela se apresenta nos estudos de folclore. Sobre as contradições na descrição da natureza e do status das lendas contemporâneas/urbanas enquanto gênero folclórico, ver os dois primeiros capítulos do clássico de Linda Dégh (2001).
} 
Os Piriás foram personagens históricos e quem conta uma história a seu respeito confere à narrativa um caráter de testemunho, além de sempre alegar a validade da ação dos irmãos como homens contaminados pelo sobrenatural. Portanto, lenda. Mas e quanto ao adjetivo contemporânea?

A necessidade de precisar o conceito se faz no sentido de delimitar o campo semântico da palavra "contemporânea". Nesse sentido, deve-se tomar o termo "contemporâneo" num sentido mais preciso: as lendas sobre os Irmãos Piriás seriam, sim, contemporâneas, já que surgem e agem num contexto de modernidade, ou melhor, de confronto com a modernidade. Não importa aqui se o contexto é rural-urbano ou se tais histórias se referem a um passado não imediato.

Outro benefício da opção por aquele encontro de culturas teóricas citado anteriormente é a possibilidade de compreensão das lendas como reflexão coletiva quanto à necessidade de atualização da hierarquia de valores diante do conflito entre valores tradicionais e modernos. As lendas sobre os Piriás têm por base a interpretação do evento como conflito que se origina de uma experiência de desrespeito social por parte de dois cidadãos simples, vindos do campo e que falham na sua socialização no meio urbano por não terem reconhecidas suas habilidades nem seu código moral. O desrespeito ao qual os dois irmãos são submetidos conforme descrito nas narrativas é violento na dupla acepção da palavra: trata-se do uso da violência a serviço da proteção de interesses privados contra o cidadão, a quem é negado o reconhecimento do status de pessoa de direito. ${ }^{10}$

Por trás desse raciocínio a ideia de adaptação ao "novo código". No caso dos Piriás, a passagem do rural para o urbano como um dos temas preferenciais das lendas. Por meio delas, as pessoas compartilham o desapontamento com a modernidade e seu código: é como se ali, na lenda, pudessem ser vividas as consequências do choque entre o código de honra tradicional e o código pretensamente urbano, jurídico, ainda que num ambiente de "modernidade

${ }^{10}$ Gillian Bennett define lendas contemporâneas como "product of social strain and social organization of the response to that strain" (Bennett; Smith, 1996, p. xxxviii). Para Linda Dégh (1984), elas comporiam uma série de scripts como respostas para problemas contemporâneos. Já Paul Smith (1996, p. 108) afirma que "contemporary legends may also function as part of the non-institutionalized system of information-dissemination and are often used to impart information about situations in the real world [...]. They disseminate and reinforce existing attitudes by stereotyping, not just people, but also beliefs and attitudes."

Horizontes Antropológicos, Porto Alegre, ano 18, n. 37, p. 185-208, jan./jun. 2012 
seletiva" (Souza, 2000). Nesse sentido, as lendas sobre os Irmãos Piriás são contemporâneas, porque tematizam a "falsa modernização", ou seja, a ampliação do status de pessoa de direito somente no nível do discurso, enquanto que, na realidade mais imediata, o que se verifica é a distância entre o reconhecimento em termos jurídicos e reconhecimento em termos de estima social.

A necessidade de refinamento do conceito também revela a não disponibilidade para a pesquisa das lendas enquanto textos acabados, independentes de outras falas no contexto narrativo. O que se pode chamar no caso de lendas sobre os Irmãos Piriás são textos ora longos, ora curtos, mais completos ou rudimentares, sempre inseridos num contexto de comunicação mais amplo, ao qual denomino, inspirada em Bergman (1987), de momento narrativo. Cada um desses momentos narrativos configura uma possibilidade de análise da narração das lendas sobre os Piriás no contexto de ações comuns. ${ }^{11}$

Logo, coloca-se a necessidade de utilizar o conceito de lenda para o caso Piriás de uma maneira mais ampla, de forma a englobar esses outros exemplares de narrativas. Para uma análise mais significativa do fenômeno, seguindo, no caso, o conselho de Linda Dégh (2001, p. 97): "I will lump together all of the materials that contain a possible legend core, and will treat them as legend unless my analysis informs me otherwise."

Sendo assim, interessam para a pesquisa todos os tipos de narrativa cujo foco se faça sobre a adequação ou inadequação de condutas e valores que entram em campo quando o tema são os Piriás. É a organização da realidade investigada que demanda um esforço maior, mas sistemático. Primeiro porque são vários os gêneros de narrativos sobre o caso Piriás que se referem à lenda: contos, cordel, reportagens, filmes, causos. Segundo porque a maioria deles se ocupa, tal qual a lenda, em analisar como indivíduos e instituições se portaram no decorrer daqueles seis meses do ano de 1978. E terceiro, porque cada uma dessas outras formas de narrar surte algum efeito sobre a lenda e pode até colaborar para sua manutenção.

E aqui se coloca outra questão fundamental quando obedecemos ao esforço de organização dos termos da realidade: a relação entre lenda e crença.

11 Os momentos narrativos analisados acontecem nos lugares mais cotidianos. Na rodoviária, numa selaria, numa capotaria, numa joalheria, numa feira, na saída da missa, numa madeireira, em salões de beleza, praça, fila de posto médico, na sala de espera de um hospital e ponto de ônibus, além de ocasiões de encontro de familiares como festas de aniversário ou almoços na casa de amigos e conhecidos.

Horizontes Antropológicos, Porto Alegre, ano 18, n. 37, p. 185-208, jan./jun. 2012 
No lugarejo chamado Córrego do Soldado, dizem que uma mulher pressentiu que havia algo de errado com a morte do filho Walace Roberto, de 14 anos, que havia sido internado no hospital de Itaúna no dia 7 de julho de 2005. Com o incentivo do patrão, a mãe pediu a exumação do corpo. Quando o caixão foi aberto, o menino estava virado de bruços, todo arranhado e com as mãos cheias de cabelo. As marcas de unha no caixão são a prova do desespero do garoto para escapar da morte. Ele havia sido enterrado vivo.

Trata-se de uma descrição dos "fatos" ou de um "produto da fantasia"? Nem uma coisa nem outra. É lenda contemporânea, matéria de capa do jornal Estado de Minas, e que procura demonstrar como a transferência do caixão de um menino para o cemitério de Itaúna, região centro-oeste de Minas Gerais, foi transformada no que os próprios jornalistas chamaram de história de terror, boato ou lenda urbana. ${ }^{12} \mathrm{O}$ esforço da reportagem é no sentido de apresentar a "verdade" sobre os "fatos". O jornalista parte do pressuposto de que o "povo" não sabe separar fato de ficção, já que a massa insiste em narrar a lenda apesar de todos os desmentidos.

Mas quem narra histórias assim "crê" necessariamente no que está narrando? Essa é a questão que tem provocado muita discussão entre os estudiosos de lendas contemporâneas. De um lado há os que defendem a associação legend/belief. De outro, os que chamam a atenção para o risco de ceder à conotação quase religiosa da palavra e ao "acreditar" como qualidade desse gênero. A mais ilustre defensora da "crença" como critério-base de qualificação do gênero lenda contemporânea é Linda Dégh (2001, p. 220), para quem "the legend-tellers are telling the truth".

Muitos críticos têm acusado Dégh de ignorar que tanto a lenda quanto a crença e mesmo o evento que a lenda descreve são constructos (Bennett, 1996). Para esses pesquisadores, apresentar a lenda contemporânea como história verdadeira seria apenas um tipo de legend performance, já que existem

\footnotetext{
12 Depois da morte do filho, declara o diretor do hospital, a família não teve dinheiro para fazer o enterro e o garoto foi enterrado em vala comum. Alguns dias depois alguém se comoveu com a história e doou um túmulo. Apesar de a troca de sepultura ter sido acompanhada por policiais, apesar de o caixão ter permanecido o tempo todo fechado (segundo declaração do delegado), apesar de o diretor do hospital e a própria mãe dizerem que é mentira, a lenda passou a circular na cidade inclusive via internet. A lenda termina assim: "Só agora isso começa a vir à tona, pois tem gente graúda que não quer que a população fique por dentro desse assunto." (Estado de Minas, 02/10/2005, p. 22).
}

Horizontes Antropológicos, Porto Alegre, ano 18, n. 37, p. 185-208, jan./jun. 2012 
aqueles que narram antilendas, histórias onde se encontram frequentes marcações que explicitam um esforço de neutralização, de racionalização do extraordinário.

Vejamos um exemplo desse esforço a partir de um momento narrativo registrado por mim no dia 05/01/2007, na rodoviária de Sete Lagoas, durante um bate-papo sobre os Piriás.

A: Bom, tô vendendo pelo preço que comprei. Dizem que o Piriá tinha ameaçado o tal do turco, o Culego...

B: Mas, no fim, foi a polícia que fez a imagem deles, né? Porque a polícia faz a imagem do matador.

A: É! Mas corria que eles desaparecia à força de reza brava, que eles tinha parte com o capeta, aquele trem de interior. E cada vez mais a polícia ficava mais com raiva por causa disso, que não punha a mão neles de jeito nenhum e tal coisa e tal. Essa de reza brava eu mesmo escutei foi muito. Que eles tinha reza que protegia eles. Diz que a polícia começava a trocar tiro com eles e ele sumia na frente da polícia. Tem gente que conta e acredita. Sei não... Na verdade acho que é bobagem. Tem gente que acredita até que ele virava cupim.

[Comentário meu:] Eu já ouvi sobre isso mesmo.

B: Nas conversas a gente sempre escutava isso, ah, que Piriá tem parte com o capeta. Está na frente da polícia, a polícia atira neles, eles some, vira cupim, vira num sei o quê...

A: É! Mas eu sempre digo assim: gente, deixa de bobagem. Gente, manda esse aí que tem reza brava, leva lá num país desses ruim, que tem guerra entre eles lá, revolução, golpe de estado, essas coisa, e coloca ele na frente da metralhadora pra nós ver o resultado que vai ser. A gente tem que ter na cabeça que o dia que isso valesse alguma coisa, todas as guerra, eles iam contratar feiticeiro, tudo quanto há. Tem que tirar essa bobajada da cabeça, gente. Você não acha?

O trecho exemplifica bem o que Dégh chama de "crença" e cria um problema para os seus críticos. Para ela, a crença não se restringe à figura do narrador. No caso, "explicitly or implicitly, the legend must make it clear that its messages is or was believed by someone, sometime, somewhere" (Dégh, 2001, p. 140). Ela prossegue:

It is not the positive declaration of belief that makes a legend a legend but rather the debate of participants considering the legend's believability. (Dégh, 2001, p. 311). 
O tratamento que Dégh dá à questão cobre o spectrum de opções performativas da lenda como verdade e como fantasia (nos termos "o povo dizia...", "falam por aí...", ouvi dizer que...", "estou vendendo pelo preço que comprei”). Como vemos no momento narrativo transcrito acima, não é preciso que um narrador acredite na lenda para que narre uma boa história. Mesmo porque não se trata de um narrador. Basta que aqueles que participam do momento narrativo creiam estar reproduzindo uma realidade.

O que Dégh esclarece, por fim, é que a lenda não deriva sua substância da certeza documental do evento. Para ela, trata-se de um gênero que nasce das esperanças e temores contemporâneos e por isso mesmo trabalha com uma credibilidade dupla: de um lado a explicação por meio de uma lógica racional; de outro uma lógica do extraordinário. $\mathrm{O}$ fato de uma ou outra lógica prevalecer no relato é sempre questão de opção e não tem nada a ver com a questão de acreditar ou não na lenda. ${ }^{13} \mathrm{O}$ que a narração da lenda faz é apresentar o problema da crença. Assim, quem participa do momento narrativo de uma lenda contemporânea sempre precisa assumir "a stand and calls for the expression of opinion in the question of truth and belief" (Dégh, 1971, p. 67). ${ }^{14}$

Vale dizer: a reação positiva ou negativa ao lendário não muda a qualidade e consequente apreciação da história. Falamos aqui de uma prática cultural que, se por um lado encontra seu fundamento em materiais legados pela tradição, por outro sujeita esse mesmo material à supervisão e à censura. Portanto, não há que se falar nem de ingenuidade nem de irracionalismo. Lendas como as dos Piriás são destinadas ao grupo social mais amplo, num processo de articulação de "verdades" específicas. Por isso, há que se falar de histórias engrandecidas pelo "gênio popular", muito menos de uma verdade alterada pela "ingenuidade" popular. Falamos de um processo em que cabem divergências de opiniões, confronto de informações concernentes ao caso e muito interessadas na moral da história.

O momento de narração dessas histórias é um momento de debate intenso e vivo em que os interlocutores estabelecem tópicos a partir da identificação

13 Principalmente quando só se considera o ponto de vista do narrador.

14 "Legendry is expressive rhetoric promoting a position on the question of authenticity and veracity of is content. While the exact nature of personal subject belief is irrelevant, it seems to be a rule that the general reference to belief is an inherent and most outstanding feature of the folk legend." (Dégh; Vázsonyi, 1971, p. 304). 
de pessoas, datas, lugares relativos ao evento contribuindo com detalhes sobre o seu desenvolvimento narrativo considerados significativos. Todos os participantes são coproponentes e todos se apresentam com suas crenças (ou melhor, "verdades") para a conclusão da narrativa. O processo está sempre aberto às proposições dos outros, e dura enquanto as pessoas tiverem tempo disponível para estarem juntas. Narrar uma lenda sobre os Piriás é, portanto, articular "verdades" culturalmente específicas. Uma articulação que é realizada pelos indivíduos na narr-ação.

As lendas sobre os Piriás envolvem, fundamentalmente, uma discussão sobre a conduta da polícia como braço armado do Estado. São histórias que fazem uma avaliação minuciosa dessa instituição e que questionam sua legitimidade, numa ação que continua atual 30 anos depois dos fatos. Daí a necessidade de decisão por uma abordagem que reconheça na narração dessas lendas uma reação interpretativa ao problema da relação entre sociedade civil e instituição policial. Essa opção afasta-se de uma análise meramente simbólica das lendas. Mas também afasta a imagem da lenda como forma organizada de defesa de direitos e valores morais tradicionais ameaçados pela sociedade moderna (e pela polícia em particular). A questão é bem mais delicada e merece ser discutida com o devido cuidado, inclusive considerando a responsabilidade na construção social da imagem de uma instituição fundamental. Aqui, contudo, basta chamar a atenção para a possibilidade de se analisar as lendas sobre os Piriás como comunicação (mais que como representação), no sentido de que ao narrar essas histórias as pessoas participam de um processo de formação e legitimação de um senso moral e de justiça muito específicos. A essência dessa práxis: o repúdio a certos aspectos da estrutura social e que implicam práticas desumanas, o estigma produzido pela prisão ilegal e suas consequências sociais reais, além da denúncia do desamparo frente às instituições públicas. As pessoas que contam histórias sobre os Piriás conhecem e sabem da continuidade de todas essas formas de não reconhecimento social. E se a questão que define os critérios de avaliação do comportamento no espaço público é questão política, não há como ignorar uma dimensão política das lendas enquanto ação narrativa, que concorre para o reconhecimento de seus critérios.

Todavia, não nos é permitido tratar as lendas como ação de uma coletividade nos seus aspectos ritualizados. O pressuposto metodológico da existência a priori da comunidade não ajuda em nada no caso da tentativa de 
apreensão dessa realidade. Isso porque a legitimação que as lendas perseguem não vem do fato de elas serem acionadas com a finalidade de defender direitos e costumes tradicionalmente definidos ("comunitários", no sentido mais coletivizante da palavra) com antecedência. Pelo contrário: o que pude perceber no decorrer da pesquisa é que, ao narrar essas histórias, um consenso vai sendo negociado (e mesmo confirmado já na circulação das lendas). Não é um consenso que existe a priori, fruto perfeito de uma visão de mundo coletiva homogênea. $O$ consenso do qual trata a lenda tem caráter de constructo, produto de uma negociação de visões de mundo e formas de apropriação do evento no contexto de narração.

Nas lendas focalizam-se o significado, as motivações da ação dos Piriás sendo que a narrativa em si procura constituir-se como meio de legitimar essa ação. Nos relatos, afirma-se que os irmãos agiram com base em uma certeza moral e um senso de justiça muito específicos. Mais que ajustar o ato dos irmãos num contexto simbólico coerente, o que se faz nas lendas é dotar suas ações de legitimidade. Portanto, mais que um ritual comunitário, o foco de análise é o comportamento daqueles que narram esse tipo de história, que revela as lendas como "formas de descrever e de interpretar experiências sócioculturais" (Turner, 1974, p. 64), sim. Mas experiências que, ao contrário do que afirmou Turner, são formuladas. As lendas em si como formulações de experiências.

Vem da antropologia de Turner (1974, p. 46) a inspiração para a análise processual dessas narrativas como algo que surge da experiência de interação ("as arising in the experience of human coactivity"). De Turner (1974, p. 6) deve-se seguir um conselho: se livrar daquela desconfiança difusa com relação ao imaginativo e emocional como empecilho para o reconhecimento do importante aspecto racional dessas narrativas populares. Nessa linha, a pesquisa se faz na busca dos indícios para a compreensão tanto do pensamento quanto do sentimento das pessoas sobre suas relações com as instituições no ambiente social em que operam. E do narrar como busca de apreensão da realidade, no caso das lendas, por meio de critérios morais. Mais uma vez, a narração como luta por reconhecimento de um modo de existência social.

Daí a preocupação com as "mediações morais" das quais nos fala o historiador da cultura, tão afinado com os estudos de cultura popular, E. P. Thompson (2005). Mais que desvendar "formas invisíveis de ação", cabe ao pesquisador assumir que narrar lendas é uma forma de ação bem visível de

Horizontes Antropológicos, Porto Alegre, ano 18, n. 37, p. 185-208, jan./jun. 2012 
configuração da própria história, onde os termos "comunidade" e "legitimidade" aparecem interligados segundo um determinado senso de finalidade que visa tanto avaliação quanto validação e motivação de comportamentos. Nas lendas sobre os Piriás concepções morais são atualizadas de forma que a narrativa adquira esse impacto diretivo sobre as formas de ação dos indivíduos.

Enfim, depois de apresentar como foi conduzida a pesquisa - como se deu a redução, a "síntese da realidade" que permitiu sua apreensão a partir da seleção de seus termos - podemos voltar à reflexão sobre a antropologia depois do fim da teoria. $\mathrm{O}$ diário de pesquisa resumido acima deixa claro que o que realmente importa não é se Piriás, polícia e fazendeiro eram tudo o que se diz que eles eram. O que realmente importa no caso da pesquisa antropológica não são os fatos como fundamento da narrativa histórica. $\mathrm{O}$ que realmente importa é como as pessoas constroem o sentido do evento, selecionando-lhes os termos, para depois tomarem a narrativa como suporte moral e justificação de suas iniciativas. Uma forma de racionalidade que pode ser analisada, alcançada sim pela narrativa antropológica.

O que leva à conclusão de que tal investigação também configura mais uma forma de racionalidade, como afirmam os pós-modernos e reconhece o próprio Rickert. Todavia, diferentemente da anterior (dos "nativos"), a racionalidade produzida pela pesquisa opera também com valores, embora outros: tem que considerar o peso dos valores culturais e interesses que concorrem na produção da pesquisa. Não poderia ser de outra forma, depois de Foucault. Um trabalho científico configura-se sempre como uma forma de "produção da verdade", como função de um poder capaz de criar sua própria legitimação. Não temos condições morais de negar isso.

A aproximação dos termos de Rickert nos afasta dos termos de Weber e seu ideal de neutralidade axiológica. A consciência dos valores no caso não significa a neutralização do esforço ou mesmo da ideia de antropologia como ciência. Se valores determinam a seleção dos termos da realidade a ser analisada e se apresentam como precondição da organização científica do conhecimento sobre a realidade é porque o tema privilegiado da antropologia, bem como da história e da sociologia, são discursos (nossos e dos outros). Devemos estar atentos aos seus "efeitos de realidade" como reclama a visão de mundo pós-moderna. Mas se olharmos nosso trabalho através da lente da filosofia da ciência de Rickert, nos livramos do pessimismo atávico que condena nossa atividade. 
A reflexão sobre valores e ciência nos remete a Fichte, a quem Rickert tanto admirava e a quem deve o fundamento de sua doutrina da ciência histórica: a ciência, bem como a razão, se define como aquilo que consiste precisamente em obter, em termos morais - ou racionais, o que dá no mesmo - noções sobre as coisas. A verdadeira ciência permite reação ao dado; para além da mera identificação às coisas. Constitui, portanto um efeito de afirmação do espírito, que por meio de sua atividade intelectual (e política!) promove a vontade moral que "cria" valores no mundo, para além do exercício de mera descrição dos fatos ou de pura especulação metafísica.

No fim, a pergunta que se coloca é o que significa o divórcio entre ciência e valor. Diríamos com Marianne Weber (por ironia, a esposa do idealizador da Wertfreiheitstheorie): significa nada menos que desistir da ideia de homem como ser em torno do qual tudo enobrece. $\mathrm{O}$ fundamento de pensamento tão nobre está na Wissenschaftlehre de Fichte. Mas isso é tema para uma próxima oportunidade de engajamento na defesa da antropologia.

\section{Referências}

BENNETT, G. Legend: performance and truth. In: BENNETT, G.; SMITH, P. (Coord.). Contemporary legend: a reader. New York: Garland Publishing, 1996. p. xvii-xl.

BERGMANN, J. Klatsch: zur Sozialform der diskreten Indiskretion. Berlin: Walter de Gruyter, 1987.

CLIFFORD, J. Sobre a autoridade etnográfica. In: CLIFFORD, J. A experiência etnográfica. Rio de Janeiro: Editora UFRJ, 1998. p. 17-62.

CRAPANZANO, V. O dilema de Hermes: o mascaramento da subversão na descrição etnográfica. Teoria e Sociedade, v. 2, n. 12, p. 106-137, 2004.

DÉGH, L. The 'belief legend' in modern society: form, function, and relationship to other genres. In: HAND, W. (Coord.). Amerikan folk legend: a symposium. Berkeley: University of California Press, 1971. p. 55-68.

DÉGH, L. Erzählen, Erzähler. In: ENZYKLOPÄDIE DES MÄRCHENS. Berlin: Walter de Gruyter, 1984. v. 4, p. 315-342. 
DÉGH, L. Legend and belief: dialectics of a folklore genre. Bloomington: Indiana University Press, 2001.

DÉGH, L.; VÁZSONYI, A. Legend and belief. Genre, v. 3, n. 4, p. 281-304, 1971.

ELIADE, M. Von Zalmoxis zu Dschingis Khan: Religion und Volkskultur in Südosteuropa. Frankfurt am Main: Insel, 1982.

GELLNER, E. Razão e cultura. Lisboa: Teorema, 1992.

HONNETH, A. Luta por reconhecimento. São Paulo: Editora 34, 2003.

KOFES, S. Uma trajetória em narrativas. Campinas: Mercado das Letras, 2001.

MADAN, T. N. Pathways: approaches to the study of society in India. Dehli: Oxford University Press, 1994.

MARCUS, G. O que vem logo depois do "pós": o caso da etnografia. Revista de Antropologia, n. 37, p. 7-34, 1994.

MARCUS, G.; FISCHER, M. A crisis of representation in the human sciences. In: MARCUS, G.; FISCHER, M. Anthropology as cultural critique. Chicago: The University of Chicago Press, 1986. p. 7-16.

PEIRANO, M. A teoria vivida e outros ensaios de antropologia. Rio de Janeiro: Jorge Zahar, 2006.

RICKERT, H. Die Grenzen der naturwissenschaftlichen Begriffsbildung: eine logische Einleitung in die historischen Wissenschaften. Tübingen: J. C. B. Mohr, 1921.

RICKERT, H. Introducción a los problemas de la filosofia de la historia. Buenos Aires: Nova, 1961.

ROSALDO, R. Subjectivity in social analysis. In: SEIDMAN, S. (Org.). The postmodern turn. Cambridge: Cambridge University Press, 1990. p. 171-183. 
SMITH, P. Contemporary legend: a legendary genre? In: BENNETT, G.; SMITH, P. (Coord.). Contemporary legend: a reader. New York: Garland Publishing, 1996. p. 104-112.

STEHR, J. Sagenhafter Alltag. Frankfurt am Main: Campus Verlag, 1998.

SOUZA, J. A modernização seletiva. Brasília: Editora da UNB, 2000.

THOMPSON, E. P. Costumes em comum: estudos sobre cultura popular tradicional. São Paulo: Companhia das Letras, 2005.

TURNER, V. O processo ritual. Petrópolis: Vozes, 1974.

Recebido em: 17/02/2011

Aprovado em: 10/11/2011 